\title{
Care management for Type 2 diabetes in the United States: a systematic review and meta-analysis
}

\author{
Jason S Egginton ${ }^{1,2}$, Jennifer L Ridgeway ${ }^{2}$, Nilay D Shah ${ }^{1,2}$, Saranya Balasubramaniam¹, Joann R Emmanuel',
} Larry J Prokop ${ }^{1}$, Victor M Montori ${ }^{1,3}$ and Mohammad Hassan Murad ${ }^{1,2,4^{*}}$

\begin{abstract}
Background: This systematic review and meta-analysis aims at assessing the composition and performance of care management models evaluated in the last decade and their impact on patient important outcomes.

Methods: A comprehensive literature search of electronic bibliographic databases was performed to identify care management trials in type 2 diabetes. Random effects meta-analysis was used when feasible to pool outcome measures.

Results: Fifty-two studies were eligible. Most commonly reported were surrogate outcomes (such as HbA1c and $\mathrm{LDL}$ ), followed by process measures (clinic visit or testing frequency). Less frequently reported were quality of life, patient satisfaction, self-care, and healthcare utilization. Most care management modalities were carved out from primary care. Meta-analysis demonstrated a statistically significant but trivial reduction of $\mathrm{HbA1c}$ (weighted difference in means $-0.21 \%, 95 \%$ confidence interval -0.40 to $-0.03, \mathrm{p}<.03$ ) and LDL-cholesterol (weighted difference in means $-3.38 \mathrm{mg} / \mathrm{dL}, 95 \%$ confidence interval -6.27 to $-0.49, \mathrm{p}<.02$ ).

Conclusions: Most care management programs for patients with type 2 diabetes are 'carved-out', accomplish limited effects on metabolic outcomes, and have unknown effects on patient important outcomes. Comparative effectiveness research of different models of care management is needed to inform the design of medical homes for patients with chronic conditions.
\end{abstract}

Keywords: Chronic Care: disease management/care management, Endocrinology: diabetes, Evidence-based medicine/critical review of evidence

\section{Background}

Chronic care delivery continues to represent a challenge to the healthcare system. New ways to deliver and manage care for patients with chronic conditions such as type 2 diabetes emerged in the late 90s, notably the Chronic Care Model [1]. In 2003, a revision formalized the need for care management [2]. Since then, many approaches have emerged to implement the Chronic Care Model, including those emphasizing the components of self management support and links to community resources. However, many care management models are offered in

\footnotetext{
* Correspondence: Murad.mohammad@mayo.edu

'Division of Preventive Medicine and the Knowledge and Evaluation

Research Unit, 200 First Street SW, 55905 Rochester, MN, USA

Full list of author information is available at the end of the article
}

a carved-out approach-not integrated with the rest of the patients' care, and their effectiveness despite their popularity remains unknown. Care management programs in chronic diseases such as diabetes, congestive heart failure and asthma can be associated with reduced length of hospitalization and medical costs and increased proportion of patients receiving appropriate medications and tests [3].

We conducted a systematic review and meta-analysis of recent controlled trials to summarize the emerging evidence of comparative effectiveness of care management modalities applied to the care of patients with type 2 diabetes across pertinent outcomes. Our focus on the last decade and on type 2 diabetes stems from the need to account for the evolving role of care management and to

\section{Biomed Central}


reflect advances in disease management that have favored type 2 diabetes.

\section{Research design and methods}

This report adheres to the preferred reporting items for systematic reviews and meta-analyses statement (the PRISMA statement) [4].

\section{Literature search strategy}

A comprehensive search of several databases (from 1/1/ 2000 through 9/21/2011) was designed and conducted by a reference librarian with input from the study's principal investigator. The databases included Ovid Medline In-Process \& Other Non-Indexed Citations, Ovid MEDLINE, Ovid EMBASE, Ovid Current Contents, Ovid Cochrane Central Register of Controlled Trials, Ovid Cochrane Database of Systematic Reviews, and EBSCO Cumulative Index to Nursing and Allied Health Literature. Controlled vocabulary supplemented with keywords was used to define the concept areas, diabetes, care management, and treatment outcomes, as well as to limit to controlled trials. The detailed search strategy is available in Additional file 1: APPENDIX.

\section{Inclusion criteria and data extraction}

Three reviewers applied the following inclusion criteria to the abstracts, with each reviewer evaluating two-thirds of the search selections to ensure dual coverage of each abstract: (1) Did the study test a care management intervention in the US on patients with type 2 diabetes? (2) Was the intervention group compared to a control group, such as patients who received usual care? We included studies in which the control group received usual care, attention control, low intensity control interventions, or other types of control groups.

Abstracts that were endorsed by at least one reviewer were included after the initial screening. Citations were kept to request full articles if they were ambiguous. After the full articles were retrieved, each of the three reviewers was assigned the full texts, with a duplicative process again employed to assure dual coverage of each article. Each full article was then evaluated on the criteria above. Endorsement by two reviewers reaching consensus was necessary for an article to be included in the final data extraction and analysis. The agreement among reviewers was adequate, $($ median kappa statistic $=.82$ ).

The primary aim of this systematic review is to describe the available care models in terms of delivery method and team composition and the outcomes they reported (process measures such as testing and visit rates, self-care, quality of life, patient satisfaction, healthcare utilization/ cost, and as a secondary aim, surrogate outcomes such as HbA1c and LDL-cholesterol).

\section{Data analysis}

\section{Delivery method}

We assigned each study to a primary delivery type "Office" if the intervention involved primarily interaction or chart review in the medical outpatient setting; "Web" if most interaction took place on the computer or internet; "Telephone" if the intervention took place over the phone or a pager system; and "Education" if the patient received educational information in another setting such as a community-based facilitated diabetes group.

\section{Leader type}

If one of the primary leaders of the intervention was discernibly a physician, we determined the trial was "Physician Led." If the intervention was led by a multidisciplinary team or an individual in another type of position, such as a diabetes nurse educator, it was categorized "Not Physician Led."

\section{Study description}

Study attributes were collected for each article including a description of the enrolled participants and the study setting; detail about the type, duration, frequency and mode of the intervention, as well as information about the control condition; and outcome measures.

\section{Study quality}

To assess the methodological quality of the described studies, we noted the how randomization and allocation concealment were conducted, whether there were important study arm imbalances at baseline or significant loss to follow up.

\section{Analysis}

We planned to conduct meta-analysis if data were available and appropriate for statistical pooling. For the continuous outcomes of hemoglobin A1c and LDL cholesterol, we estimated the difference in means from each study with $95 \%$ confidence interval $(\mathrm{CI})$. The difference in means is estimated as the difference between the change in the intervention arm and the change in the control arm so that a negative value indicates more decline the intervention arm (i.e., a negative value implies results favoring the care management program). $95 \%$ CI that overlaps a value of zero implies no statistically significant effect and is analogous to a 2-tailed p value $>0.05$. We pooled the differences in means across studies using the random effects model because of anticipated heterogeneity of the included studies (in terms of design, populations and interventions) [5]. The random effects model incorporates within-study heterogeneity in the $\mathrm{CI}$ and produces more conservative estimates. A priori subgroup analyses were defined based on team composition (physician led vs not), delivery method (web vs phone vs office vs education) and length of follow up ( $\leq 1$ year vs. $>1$ year) and used to explain heterogeneity by conducting a test of interaction [6]. Heterogeneity was evaluated using the $\mathrm{I}^{2}$ statistic with 
values $>50 \%$ consistent with substantial heterogeneity [7] Meta-analysis was conducted using Comprehensive MetaAnalysis, version 2 software [8]. When meta-analysis was not feasible, (i.e., no reported hemoglobin A1c or LDL values or missing measures of precision such as standard deviations and sample sizes for two time points), we presented description of the individual studies in terms of design, care model characteristics and conclusions.

\section{Results}

Figure 1 displays the results of our search process. The literature search yielded 1636 abstracts from which 52 proved eligible for inclusion.

\section{Study features}

Additional file 1: Table S1 details the characteristics of included studies (median number of enrolled patients is 266 , mean study duration is 14 months; and the length of follow-up ranged from a few weeks (49), to 5 years (57). Studies varied by geographic area and clinical team composition.

Criteria for patient enrollment also varied considerably. Some studies focused on specific socioeconomic or demographic characteristics [9-16], while others identified patients based on $\mathrm{HbA} 1 \mathrm{c}$ level requirements [12,18-26]. In 11 of the studies, enrolled patients were included or excluded based on HbA1c levels (most typically requiring an elevated $\mathrm{HbA} 1 \mathrm{c}$, e.g., > 8\%). A minimum age, or age range, requirement was used in several studies [9,10,13,26-30].

Forty-two of 52 were parallel randomized controlled trials. The other nine studies followed a clustered randomization of physician panels or practices, or were a

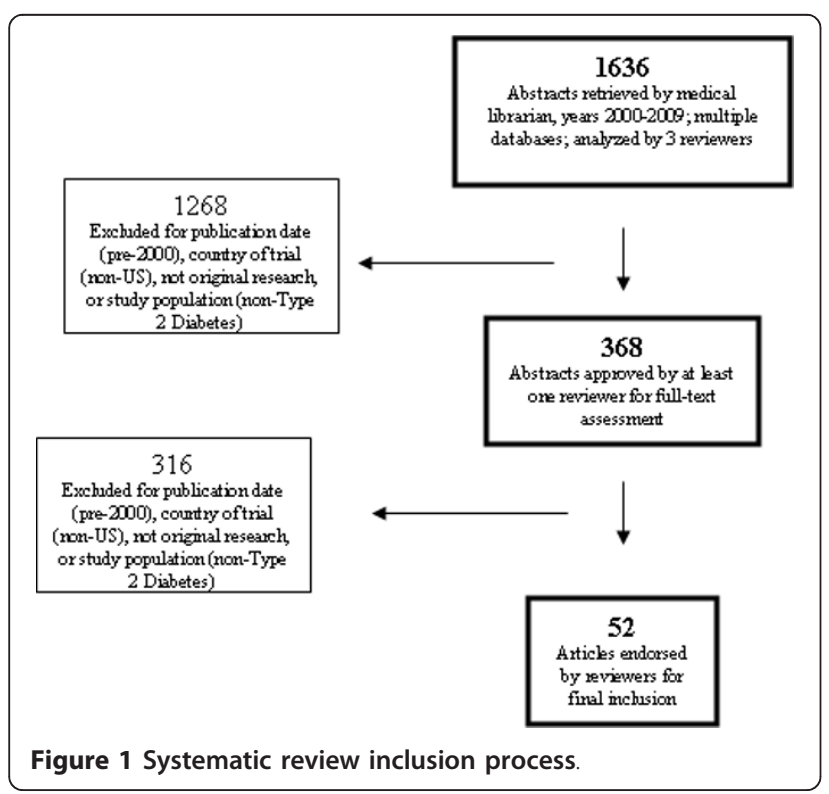

comparison of two practices. One study was a modelbased predictive trial using actual patient data; another looked at before-after data regarding implementation of electronic medical records. The quality of the randomized trials was fair. Some of the methodological limitations noted were lack of reporting of allocation concealment and high or unclear loss to follow up rates. Blinding care givers and patients in this evaluation was not feasible as expected. Cluster randomized trials did not clearly address the issue of contamination. The nonrandomized studies were in general of good quality with adequate adjustment for confounders and apparent baseline prognostic balance of the two study arms. Study quality is described in Additional file 1: Table S2.

\section{Delivery method}

Office interventions were the most common, being used in $67 \%$ of studies. Telephone and education were next, followed by web interventions, which were only used in seven studies (15\%). Thirty-nine percent of studies employed more than one type of intervention (office, telephone, web or education). With the 33 office interventions, nearly half also utilized a telephone or education intervention. Intervention delivery methods and outcomes measured are described in Additional file 1: Figure S1. The care management program was carved out of primary care practice in $36 / 52$ (69\%) of the studies.

\section{Intervention leadership}

In 15 of the 52 studies in this review, a physician can be discerned as the leader of the intervention; in the other 36, another professional or group of professionals was identified as facilitating the trial. All physician-led interventions were delivered in the office setting (compared to about half of non-physician-led interventions). Two of the physician-led interventions also had a telephone intervention component, and another two had an education component. The distribution of study leadership and the method of delivery are detailed in Additional file 1: Table S3.

\section{Study outcomes}

Figure 2 displays the reported outcomes across studies. Seventy-three percent of studies reported more than one outcome, with an average of two. Additional file 1: Table S4 details the outcomes for each of the 52 studies.

The most commonly reported results were surrogate outcomes, such as HbA1c and LDL-cholesterol. Eightyfive percent of studies included such an outcome, and 30 of those $(71 \%)$ found statistically significant results. However, in some cases (e.g. Piette et al.) [29], the significance reported was limited to a specific subgroup, the high-risk group. In other cases, the authors only 


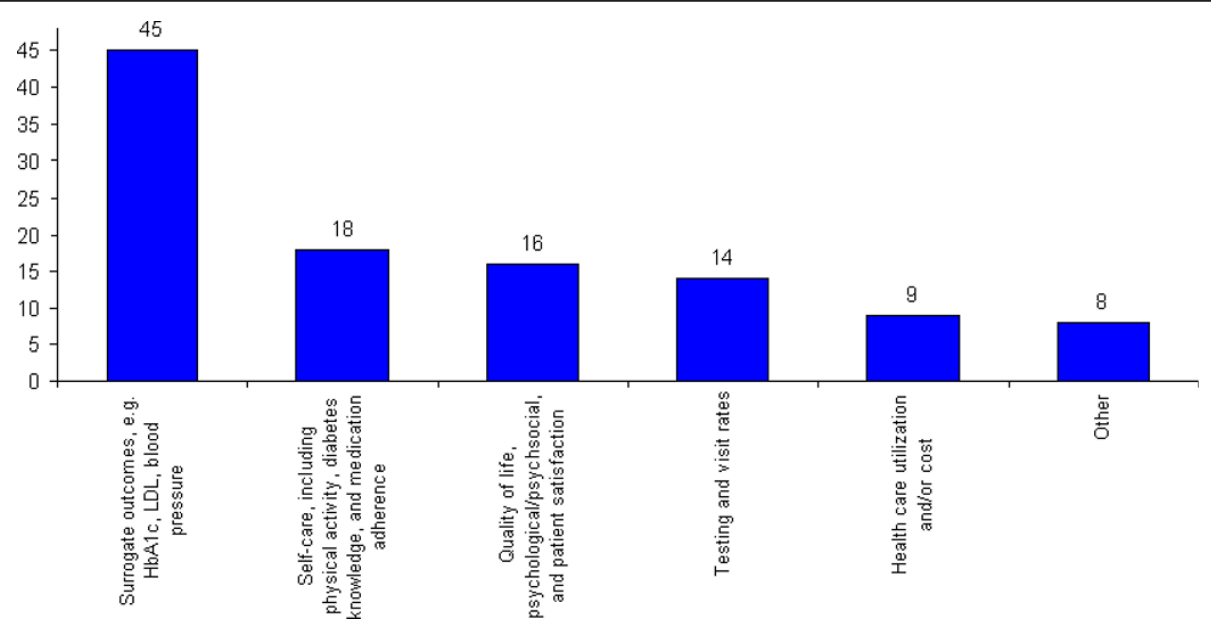

Figure 2 Types of reported outcomes.

found significant differences between intervention and control groups on a few of the measured surrogate outcomes [13,26,31-36].

Studies also evaluated the impact of $\mathrm{CM}$ interventions on process measures (e.g., adherence to disease monitoring protocols such as getting the recommended number of cholesterol tests in eligible populations). Fourteen studies included at least one process outcome, and all of these also had some type of surrogate outcome measurement. Eleven of the 14 studies found some significant results on at least one process measure, but there were mixed results on whether those same studies also achieved desirable surrogate outcomes. In one example, the authors found that a pharmacist-led intervention resulted in significant differences between intervention and control groups on LDL measurement, retinal exam, and foot exam rates [17].

Reductions in HbA1c level were significant, especially among patient with the highest blood levels. In another study, the authors did not find significant results on changes in cholesterol or HbA1c levels, but they did get significant results on 10 American Diabetes Association standards of care measures-a result they surmise may be related to small sample size and short study duration [12]. In another example, [37] improvements in care processes did not translate into improved surrogate outcomes, possibly because baseline levels were relatively good. There were also some associations between outcomes measured.

All but one of the studies that looked at testing or visit rates also measured surrogate outcomes. And in 70 percent of cases, significant results on testing and visit rates were associated with significant surrogate outcomes.

Self-care outcomes were included in nineteen, and ten of these demonstrated positive change. There were a range of self-care measures including foot exams and self-monitoring glucose. Seven of the studies mentioned diet or nutrition as part of the intervention.

There were seventeen studies with quality of life outcomes (including patient satisfaction-related outcomes), with twelve reporting at least one significant improvement. Eight studies included some measure of health care cost or utilization (2 with significant change), although most of them included this as a secondary measure. The "other" category captures outcomes such as the number of risky prescribing events. Only two of those studies achieved statistically significant outcomes.

Physician-led studies primarily focused on surrogate outcomes and measures like visit or testing rates. There were less likely to include outcomes like self-care or quality of life although this comparison is not statistically significant due to the small number of studies (Additional file 1: Figure S2).

\section{Meta-analysis of HbA1c and LDL outcomes}

While 48 studies included some type of surrogate outcome, only 29 provided data sufficient for meta-analysis (seventeen of these reported complete HbA1c measures, twelve reported complete LDL measures, and ten reported both).

Results of the meta-analyses are shown in Figures 3 and 4. Diabetes care management interventions were associated with a statistically significant reduction in hemoglobin A1c level (weighted difference in means -0.22\%; 95\% CI -0.40 to $-0.04 ; \mathrm{p}=0.02$ ). This reduction however, was also associated with significant heterogeneity $\left(\mathrm{I}^{2}=94 \%\right)$ and is unlikely to be clinically important. The trend in reduction in LDL associated with these programs was statistically significant (weighted difference in means - 3.38 $\mathrm{mg} / \mathrm{dL} ; 95 \% \mathrm{CI},-6.27$ to $-0.49 ; \mathrm{p}=0.02$ ). This analysis was not associated with significant heterogeneity $\left(\mathrm{I}^{2}=27 \%\right)$, and was again trivial from a clinical standpoint. 


\section{Hemoglobin A1C}

\begin{tabular}{lrrrr}
\hline Study name & \multicolumn{5}{c}{ Statistics for each study } \\
& $\begin{array}{c}\text { Difference } \\
\text { in means }\end{array}$ & $\begin{array}{c}\text { Lower } \\
\text { limit }\end{array}$ & $\begin{array}{c}\text { Upper } \\
\text { lnit }\end{array}$ & p-Value \\
CA, group, 2004 & -0.77 & -0.81 & -0.73 & 0.00 \\
Gabbay, 2005 & 0.01 & -0.46 & 0.48 & 0.97 \\
King, 2009 & -0.80 & -1.53 & -0.07 & 0.03 \\
McMahon, 2005 & -0.40 & -1.02 & 0.22 & 0.21 \\
O'Connor, 2009 A3 & 0.05 & -0.15 & 0.25 & 0.63 \\
Shea, 2006 & -0.13 & -0.34 & 0.08 & 0.22 \\
Shea, 2009 & -0.25 & -0.45 & -0.05 & 0.01 \\
Smith, 2008 & 0.00 & -0.53 & 0.53 & 1.00 \\
Wolf, 2004 & -1.00 & -1.68 & -0.32 & 0.00 \\
Stroebel, 2002 B & -0.10 & -0.47 & 0.27 & 0.60 \\
scott 2006 & -1.02 & -1.68 & -0.36 & 0.00 \\
Choe, 2005 & -1.20 & -2.29 & -0.11 & 0.03 \\
Glasgow, 2000 C & 0.10 & -0.62 & 0.82 & 0.78 \\
Hirsch, 2002 & -0.67 & -1.47 & 0.13 & 0.10 \\
Hiss, 2007 & -0.20 & -0.27 & -0.13 & 0.00 \\
Kennedy, 2006 A. & 0.20 & 0.05 & 0.35 & 0.01 \\
Kennedy, 2006 B & 0.10 & -0.05 & 0.25 & 0.19 \\
Kennedy, 2006 C & 0.20 & 0.05 & 0.35 & 0.01 \\
Leu, 2005 & 0.30 & -0.64 & 1.24 & 0.53 \\
Lorig, 2008 & -0.36 & -0.83 & 0.11 & 0.13 \\
O'Connor, 2005 A & 0.20 & -0.63 & 1.03 & 0.64 \\
O'Connor, 2005 B & 0.10 & -0.19 & 0.39 & 0.50 \\
Odegard, 2005 & 0.40 & -0.27 & 1.07 & 0.24 \\
Piatt, 2006 A & -0.50 & -1.50 & 0.50 & 0.33 \\
Piatt, 2006 B & -0.10 & -1.04 & 0.84 & 0.84 \\
Piette, 2001 & -0.20 & -0.60 & 0.20 & 0.33 \\
Raji, 2002 & -0.10 & -0.89 & 0.69 & 0.80 \\
Ralston, 2009 & -1.10 & -2.04 & -0.16 & 0.02 \\
Rothman, 2005 & -0.80 & -1.49 & -0.11 & 0.02 \\
Thomas, 2006 & 0.40 & 0.07 & 0.73 & 0.02 \\
doucet, 2009 & -0.39 & -1.10 & 0.32 & 0.28 \\
Walker, 2011 & -0.36 & -0.69 & -0.03 & 0.03 \\
& -0.22 & -0.40 & -0.04 & 0.02
\end{tabular}

Favors care management

Favors control group

\section{Meta Analysis}

Figure 3 Meta-analysis of Hemoglobin A1c.

There was no statistically significant interaction for length of intervention and subgroup analysis showed no significant effect for type of intervention (office, web, telephone, or education) or whether a physician played a key role in the intervention. There was no statistically significant interaction for the length of the intervention (defined as $>12$ months or $\leq 12$ months) for either LDL ( $p=0.90)$ or HbA1c ( $\mathrm{p}=0.50)$, (See Additional file 1: Table S5).

\section{Discussion}

We conducted a systematic review of the literature evaluating type 2 diabetes care management interventions in the US during the last decade. We identified 52 studies that demonstrated heterogeneous results in terms of improvements in process measures and paucity of data on patient-important outcomes. We found that these interventions were associated with some improvement in surrogate outcomes (trivial reduction in hemoglobin A1c and LDL cholesterol levels). We could not identify a particular intervention type or team characteristic that is more effective.

In the available literature, many of the disease management programs were carved out of primary care practice. Traditionally, carve out programs were thought 


\section{LDL-Cholesterol}

\section{Study name}

Gabbay, 2005

Gary, 2003

King, 2009

McMahon, 2005

O'Connor, 2009

Pollard, $2009 \mathrm{~A}$

Pollard, $2009 \mathrm{~B}$

Shea, 2006

Shea, 2009

Smith, 2008

Wolf, 2004

Stroebel, 2002

scott 2006

doucet, 2009

\begin{tabular}{rrrc}
\multicolumn{5}{c}{ Statistics for each study } \\
$\begin{array}{rrrr}\text { Difference } \\
\text { in means }\end{array}$ & $\begin{array}{r}\text { Lower } \\
\text { limit }\end{array}$ & $\begin{array}{c}\text { Upper } \\
\text { limit }\end{array}$ & $p$-Value \\
-1.50 & -11.82 & 8.82 & 0.78 \\
12.70 & -4.55 & 29.95 & 0.15 \\
-9.00 & -23.57 & 5.57 & 0.23 \\
-1.00 & -12.94 & 10.94 & 0.87 \\
0.10 & -3.97 & 4.17 & 0.96 \\
2.00 & -13.61 & 17.61 & 0.80 \\
-15.00 & -35.25 & 5.25 & 0.15 \\
-8.66 & -13.99 & -3.33 & 0.00 \\
-1.00 & -5.83 & 3.83 & 0.69 \\
-2.00 & -14.77 & 10.77 & 0.76 \\
-18.00 & -33.73 & -2.27 & 0.02 \\
-2.70 & -8.63 & 3.23 & 0.37 \\
-11.20 & -27.09 & 4.69 & 0.17 \\
-7.60 & -22.69 & 7.49 & 0.32 \\
-3.38 & -6.27 & -0.49 & 0.02
\end{tabular}

Difference in means and $95 \% \mathrm{Cl}$

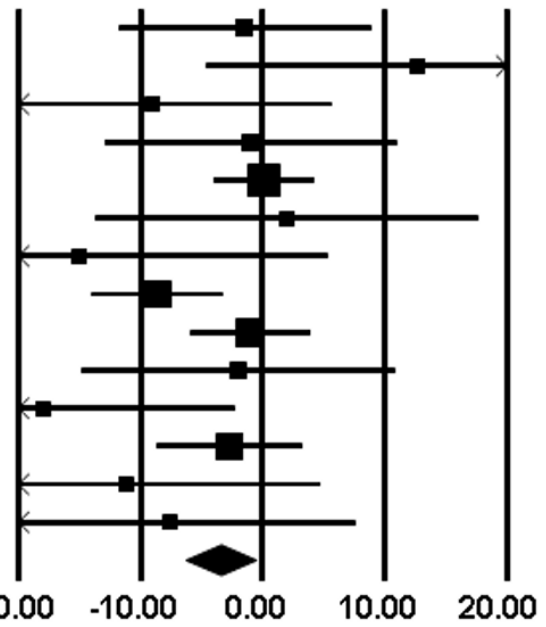

Favors care management Favors control group

\section{Meta Analys is}

Figure 4 Meta-analysis of LDL-cholesterol.

to provide the expertise that would be prohibitively expensive for health plans to develop and sustain [38]. However, this trend has changed and health practices are bringing back these programs in-house. Some of the reasons behind this change are the availability of information technology that enables the integration of databases (prescription, claims, and laboratory data); the potential misalignment of vendor and client interests; insufficient transparency and insufficient evidence of improved outcomes [38]. Moreover, integrated care is intuitively more patient-centered and may reduce redundancy. The data synthesized in this report are insufficient to recommend for or against either approach (carved vs not). Overall, the wide variations in intervention delivery methods, duration, and populations, and the use of surrogate outcomes in the included studies, further challenge inference and does not provide evidence to support the use of these models in type 2 diabetes.

The Chronic Care Model identifies the essential elements of a health care system that encourage high-quality chronic disease care. These elements are the community, the health system, self-management support, delivery system design, decision support and clinical information systems $[1,2]$. The available evidence is derived from programs that do not offer all or most of these components. Further, the studies summarized in this review do not address the recent themes of contemporary chronic care model (patient safety, cultural competency, care coordination, community policies and case management) $[1,2]$. Therefore; the efficacy of a true and practical chronic care model in type 2 diabetes remains undetermined.

\section{Comparison with other reviews}

Pimouguet et al. conducted a systematic review and metaanalysis focusing on $\mathrm{HbA1c}$ and found that care management programs were associated with a statistically significant reduction of $-0.38(-0.47$ to -0.29$)$ [39]. This effect size is similar to the one detected in the current analysis although in their analysis they pooled type 1 and type 2 diabetes studies. They found similar rates of hypoglycemia although this outcome was poorly and non systematically reported. Several other older reviews (1999-2006) also focused on A1c but some found improvements in the rates of screening for diabetic retinopathy, foot lesions, peripheral neuropathy, and proteinuria; and on the 
monitoring of lipid concentrations [40-42]. The current systematic review updates the evidence base and adds to the emerging literature on the impact, or lack thereof, of care management on patient-important outcomes.

A recent randomized trial by McCall et al. [43] assigned 242,417 patients with heart failure or diabetes to eight commercial disease-management programs using nurse-based call centers or to usual care (control). They demonstrated that the intervention did not reduce hospital admissions or emergency room visits but led to 14 (out of 40) significant improvements in process-of-care measures. These modest improvements came at substantial cost to the Medicare program ( $\$ 400$ million) with no demonstrable savings in expenditures. This trial underscores the apparent limits to the premise of care/disease management for diabetes, particularly when provided carved out of the context of primary care.

\section{Limitations and strengths}

The strength of this review stems from the focused clinical question and comprehensive literature search. We were more interested in the recent trend over the past decade in diabetes care management programs and therefore did not evaluate prior publications. We attempted to synthesize the evidence on outcomes that matter to patients although meta-analyses were only possible on surrogate laboratory outcomes. The likelihood of reporting bias and publication bias threatens the validity of this review and its presence is suggested by the selective reporting of outcomes (only a small numbers of studies reported each outcome). This review focuses on the last decade because we aimed at providing a contemporary evaluation of the current trends in these care models. Therefore, our conclusions may be biased since relevant older publications, summarized elsewhere, are not presented in this report. The evaluation of publication bias was not statistically feasible due to the small number of studies and the significant heterogeneity in results across trials [44]. Lastly, we used a consensus process to categorize study intervention methods to allow comparisons across these methods. However, assigning intervention methods to mutually exclusive categories could have biased the observed effects toward the null.

\section{Conclusion}

Best available evidence offers limited certainty about the impact of care management for patients with type 2 diabetes. Based on this limited evidence, care management improves process measures and also improves surrogate outcomes to a trivial extent. Despite that some of the included trials were of sufficient size and duration, there is almost no data regarding benefits of care management on patient-important outcomes, such as living longer and independently, feeling better, or suffering fewer complications.

In conclusion, the current literature does not allow the confident endorsement of a single model or delivery method for care management for patients with type 2 diabetes. Further research is needed to evaluate whether existing models achieve more than the ever improving usual care to improve outcomes of importance to patients.

\section{Additional material}

Additional file 1: Table S1. Study Description, $N=52$ [45-66].

\section{Acknowledgements}

The study had no funding resource. No other acknowledgments.

\section{Author details}

'Division of Preventive Medicine and the Knowledge and Evaluation Research Unit, 200 First Street SW, 55905 Rochester, MN, USA. ²Division of Health Care Policy and Research, Mayo Clinic, Rochester, MN, USA. ${ }^{3}$ Division

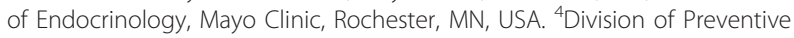
Medicine, Mayo Clinic, Rochester, MN, USA.

\section{Authors' contributions}

MHM and JSE had full access to all of the data in the study and take responsibility for the integrity of the data and the accuracy of the data analysis. MHM, VMM and NDS conceived and designed the study. SB, JRE and LJP acquired the data. MHM and JSE analyzed and interpreted the data. MHM and JSE drafted the manuscript. All authors critically revised the manuscript for important intellectual content. MHM, JSE and JLR provided administrative, technical, or material support. MHM supervised the study. All authors have given final approval for publication.

\section{Competing interests}

The authors declare that they have no competing interests.

Received: 10 November 2011 Accepted: 22 March 2012

Published: 22 March 2012

\section{References}

1. Wagner $\mathrm{EH}$ : Chronic disease management: what will it take to improve care for chronic illness? Eff Clin Pract 1998, 1(1):2-4

2. Improving Chronic Illness Care. The Chronic Care Model. 2011 [http:// www.improving chroniccare.org/index.php? $\mathrm{p}=$ The_Chronic_Care_Model\&s =2], Accessed March 21, 2001.

3. Dall TM: Askarinam Wagner RC, Zhang Y, Yang W, Arday DR, Gantt CJ: Outcomes and lessons learned from evaluating TRICARE's disease management programs. Am J Manag Care 2010, 16(6):438-446.

4. Moher D, Liberati A, Tetzlaff J, Altman DG: Preferred reporting items for systematic reviews and meta-analyses: the PRISMA statement. J Clin Epidemiol 2009, 62(10):1006-1012.

5. DerSimonian R, Laird N: Meta-analysis in clinical trials. Control Clin Trials 1986, 7(3):177-188.

6. Altman DG, Bland JM: Interaction revisited: the difference between two estimates.[see comment]. BMJ 2003, 326(7382):219.

7. Higgins J, Thompson S, Deeks J, Altman D: Measuring inconsistency in meta-analyses. BMJ 2003, 327(7414):557-560.

8. Comprehensive Meta-Analysis [computer program]. Version 2 Englewood, NJ; 2005.

9. Amoako E, Skelly AH, Rossen EK: Outcomes of an intervention to reduce uncertainty among African American women with diabetes. West J Nurs Res 2008, 30(8):928-942. 
10. Batik O, Phelan EA, Walwick JA, Wang G, LoGerfo JP: Translating a community-based motivational support program to increase physical activity among older adults with diabetes at community clinics: a pilot study of Physical Activity for a Lifetime of Success (PALS). Prev Chron Dis 2008, 5(1):A18

11. California Medi-Cal Type 2 Diabetes Study G: Closing the gap: effect of diabetes case management on glycemic control among low-income ethnic minority populations: the California Medi-Cal type 2 diabetes study.[see comment]. Diabetes Care 2004, 27(1):95-103.

12. Clancy DE, Brown SB, Magruder KM, Huang P: Group visits in medically and economically disadvantaged patients with type 2 diabetes and their relationships to clinical outcomes. Top Heal Inf Manag 2003, 24(1):8-14.

13. Gary $T L$, Bone $L R$, Hill MN, et al: Randomized controlled trial of the effects of nurse case manager and community health worker interventions on risk factors for diabetes-related complications in urban African Americans. Prev Med 2003, 37(1):23-32.

14. Leu MG, Norris TE, Hummel J, Isaac M, Brogan MW: A randomized, controlled trial of an automated wireless messaging system for diabetes. Diabetes Technol Ther 2005, 7(5):710-718.

15. McMahon GT, Gomes HE, Hickson Hohne S, Hu TM-J, Levine BA, Conlin PR: Web-based care management in patients with poorly controlled diabetes.[see comment]. Diabetes Care 2005, 28(7):1624-1629.

16. Phillips LS, Ziemer DC, Doyle JP, et al: An endocrinologist-supported intervention aimed at providers improves diabetes management in a primary care site: improving primary care of African Americans with diabetes (IPCAAD) 7. Diabetes Care 2005, 28(10):2352-2360

17. Choe HM, Mitrovich S, Dubay D, Hayward RA, Krein SL, Vijan S: Proactive case management of high-risk patients with type 2 diabetes mellitus by a clinical pharmacist: a randomized controlled trial. Am J Manag Care 2005, 11(4):253-260.

18. Elder C, Aickin M, Bauer V, Cairns J, Vuckovic N: Randomized trial of a whole-system ayurvedic protocol for type 2 diabetes. Alternative Ther Health Med 2006, 12(5):24-30

19. Krein SL, Klamerus ML, Vijan S, et al: Case management for patients with poorly controlled diabetes: a randomized trial.[see comment]. Am J Med 2004, 116(11):732-739.

20. Odegard PS, Goo A, Hummel J, Williams KL, Gray SL: Caring for poorly controlled diabetes mellitus: a randomized pharmacist intervention. Ann Pharmacother 2005, 39(3):433-440.

21. Quinn CC, Gruber-Baldini AL, Shardell M, et al: Mobile diabetes intervention study: Testing a personalized treatment/behavioral communication intervention for blood glucose control. Contemp Clin Trials 2009, 30(4):334-346.

22. Raji A, Gomes H, Beard JO, MacDonald P, Conlin PR: A randomized trial comparing intensive and passive education in patients with diabetes mellitus. Arch Intern Med 2002, 162(11):1301-1304.

23. Ralston JD, Hirsch IB, Hoath J, Mullen M, Cheadle A, Goldberg HI: Webbased collaborative care for type 2 diabetes: a pilot randomized trial. [see comment]. Diabetes Care 2009, 32(2):234-239.

24. Rothman $\mathrm{RL}$, Malone $\mathrm{R}$, Bryant $\mathrm{B}$, et al: $\mathrm{A}$ randomized trial of a primary care-based disease management program to improve cardiovascular risk factors and glycated hemoglobin levels in patients with diabetes.[see comment]. Am J Med 2005, 118(3):276-284.

25. Whitlock WL, Brown A, Moore $K$, et al: Telemedicine improved diabetic management. Mil Med 2000, 165(8):579-584.

26. Glasgow RE, Toobert DJ: Brief, computer-assisted diabetes dietary selfmanagement counseling: effects on behavior, physiologic outcomes, and quality of life.[see comment]. Med Care 2000, 38(11):1062-1073.

27. Izquierdo R, Meyer S, Starren J, et al: Detection and remediation of medically urgent situations using telemedicine case management for older patients with diabetes mellitus. Ther Clin Risk Manag 2007, 3(3):485-489.

28. Nuovo J: The impact of planned visits on patients with type 2 diabetes mellitus. Clin Med Endocrinol Diabetes 2009, 2009(2):7-14.

29. Pitale S, Kernan-Schroeder D, Emanuele N, et al: Health-related quality of life in the VA Feasibility Study on glycemic control and complications in type 2 diabetes mellitus. J Diabetes Complications 2005, 19(4):207-211.

30. Williams GC, Lynch M, Glasgow RE: Computer-assisted intervention improves patient-centered diabetes care by increasing autonomy support. Health Psychol 2007, 26(6):728-734
31. Hiss RG, Armbruster BA, Gillard ML, McClure LA: Nurse care manager collaboration with community-based physicians providing diabetes care: a randomized controlled trial. Diabetes Educat 2007, 33(3):493-502.

32. O'Connor PJ, Desai J, Solberg LI, et al: Randomized trial of quality improvement intervention to improve diabetes care in primary care settings. Diabetes Care 2005, 28(8):1890-1897.

33. O'Connor PJ, Sperl-Hillen J, Johnson PE, Rush WA, Crain AL: Customized feedback to patients and providers failed to improve safety or quality of diabetes care: A randomized trial. Diabetes Care 2009, 32(7):1158-1163.

34. O'Connor PJ, Sperl-Hillen JM, Johnson PE, et al: Simulated physician learning intervention to improve safety and quality of diabetes care: a randomized trial. Diabetes Care 2009, 32(4):585-590.

35. Thomas PD, Miceli R: Evaluation of the "Know Your Health" program for type 2 diabetes mellitus and hypertension in a large employer group. Am J Manag Care 2006, 12:SP33-SP39.

36. Wolf AM, Conaway MR, Crowther JQ, et al: Translating lifestyle intervention to practice in obese patients with type 2 diabetes: Improving Control with Activity and Nutrition (ICAN) study.[see comment]. Diabetes Care 2004, 27(7):1570-1576.

37. Glasgow RE, Nutting PA, King DK, et al: Randomized effectiveness trial of a computer-assisted intervention to improve diabetes care. Diabetes Care 2005, 28(1):33-39.

38. Sipkoff M: Is Care Coordination Making Carve-outs Less Desirable? Manag Care 2008, 11:18-20.

39. Pimouguet C, Le Goff M, Thiebaut R, Dartigues JF, Helmer C: Effectiveness of disease-management programs for improving diabetes care: a metaanalysis. Cmaj 2011, 183(2):E115-E127.

40. Knight K, Badamgarav E, Henning JM, et al: A systematic review of diabetes disease management programs. Am J Manag Care 2005, 11(4):242-250

41. Norris SL, Nichols PJ, Caspersen CJ, et al: The effectiveness of disease and case management for people with diabetes. A systematic review. Am J Prev Med 2002, 22(4 Suppl):15-38

42. Renders CM, Valk GD, Griffin SJ, Wagner EH, Van J, Assendelft WJJ: Interventions to improve the management of diabetes in primary care, outpatient, and community settings - A systematic review. Diabetes Care 2001, 24(10):1821-1833

43. McCall N, Cromwell J: Results of the Medicare Health Support diseasemanagement pilot program. N Engl J Med 2011, 365(18):1704-1712.

44. Lau J, loannidis JP, Terrin N, Schmid CH, Olkin I: The case of the misleading funnel plot. BMJ 2006, 333(7568):597-600.

45. Doucette WR, Witry MJ, Farris KB, McDonough RP: Community pharmacistprovided extended diabetes care. Ann Pharmacother 2009, 43(5):882-889.

46. Gabbay RA, Lendel I, Saleem TM, Shaeffer G, Adelman AM, Mauger DT, Collins M, Polomano RC: Nurse case management improves blood pressure, emotional distress and diabetes complication screening. Diabetes Research \& Clinical Practice 2006, 71(1):28-35.

47. Ilag Liza L, Martin Catherine L, Tabaei Bahman P, Isaman Deanna JM, Ray Burke, Greene Douglas A, Herman William H: Improving diabetes processes of care in managed care.[see comment]. Diabetes Care 2003, 26(10):2722-2727.

48. Kennedy L, Herman WH, Strange $P$, Harris A: Impact of active versus usual algorithmic titration of basal insulin and point-of-care versus laboratory measurement of $\mathrm{HbA}<$ sub $>1 \mathrm{c}</$ sub $>$ on glycemic control in patients with type 2 diabetes: The Glycemic Optimization with Algorithms and Labs at Point of Care (GOAL A1C) trial. Diabetes Care 2006, 29(1):1-8.

49. Lorig K, Ritter PL, Villa F, Piette JD: Spanish diabetes self-management with and without automated telephone reinforcement: two randomized trials. Diabetes Care 2008, 31(3):408-414

50. O'Connor PJ, Lauren Crain A, Rush WA, Sperl-Hillen JM, Gutenkauf JJ, Duncan JE: Impact of an electronic medical record on diabetes quality of care. Ann Fam Med 2005, 3(4):300-306.

51. Pettitt DJ, Wollitzer AO, Jovanovic L, He G, Ipp E: Decreasing the risk of diabetic retinopathy in a study of case management: the California Medi-Cal Type 2 Diabetes Study. Diabetes Care 2005, 28(12):2819-2822.

52. Samuel-Hodge CD, Keyserling TC, Park S, Johnston LF, Gizlice Z, Bangdiwala SI: A randomized trial of a church-based diabetes selfmanagement program for African Americans with type 2 diabetes. Diabetes Educ 2009, 35(3):439-454 
53. Scott DM, Boyd ST, Stephan M, Augustine SC, Reardon TP: Outcomes of pharmacist-managed diabetes care services in a community health center. American Journal of Health-System Pharmacy 2006, 63(21):2116-2122.

54. Sequist TD, Gandhi TK, Karson AS, Fiskio JM, Bugbee D, Sperling M, Cook EF, Orav EJ, Fairchild DG, Bates DW: A randomized trial of electronic clinical reminders to improve quality of care for diabetes and coronary artery disease. J Am Med Informat Assoc 2005, 12(4):431-437.

55. Shea S, Weinstock RS, Starren J, Teresi J, Palmas W, Field L, Morin P, Goland R, Izquierdo RE, Thomas Wolff L, Ashraf M, Hilliman C, Silver S, Meyer S, Holmes D, Petkova E, Capps L, Lantigua RA: A randomized trial comparing telemedicine case management with usual care in older, ethnically diverse, medically underserved patients with diabetes mellitus. J Am Med Informat Assoc 2006, 13(1):40-51.

56. Shea S, Weinstock Ruth S, Teresi Jeanne A, Walter Palmas, Justin Starren, Cimino James J, Lai Albert M, Lesley Field, Morin Philip C, Robin Goland, Izquierdo Roberto E, Susana Ebner, Stephanie Silver, Eva Petkova, Jian Kong, Eimicke Joseph P, I. DEATel Consortium: A randomized trial comparing telemedicine case management with usual care in older, ethnically diverse, medically underserved patients with diabetes mellitus: 5 year results of the IDEATel study. J Am Med Informat Assoc 2009, 16(4):446-456.

57. Smith Steven A, Shah Nilay D, Bryant Sandra C, Christianson Teresa JH, Bjornsen Susan S, Giesler Paula D, Kathleen Krause, Erwin Patricia J, Montori Victor M, Group Evidens Research: Chronic care model and shared care in diabetes: randomized trial of an electronic decision support system. [erratum appears in Mayo Clin Proc. 2008 Oct;83(10):1189]. Mayo Clin Proc 2008, 83(7):747-757.

58. Stroebel RJ, Scheitel SM, Fitz JS, Herman RA, Naessens JM, Scott CG, Zill DA Muller $L: A$ randomized trial of three diabetes registry implementation strategies in a community internal medicine practice. Joint Comm J Qual Improv 2002, 28(8):441-450.

59. Walker EA, Shmukler C, Ullman R, Blanco E, Scollan-Koliopoulus M, Cohen HW: Results of a successful telephonic intervention to improve diabetes control in urban adults: A randomized trial. Diabetes Care 2011, 34(1):2-7.

60. Whitlock WL, Brown A, Moore K, Pavliscsak H, Dingbaum A, Lacefield D, Buker $\mathrm{K}$, Xenakis S: Telemedicine improved diabetic management. Military Medicine 2000, 165(8):579-584.

61. Wolf Anne M, Conaway Mark R, Crowther Jayne Q, Hazen Kristen Y, Nadler Jerry L, Beverly Oneida, Bovbjerg Viktor E, Study Improving Control with Activity and Nutrition: Translating lifestyle intervention to practice in obese patients with type 2 diabetes: Improving Control with Activity and Nutrition (ICAN) study.[see comment]. Diabetes Care 2004, 27(7):1570-1576.

62. Hirsch IB, Goldberg HI, Ellsworth A, Evans TC, Herter CD, Ramsey SD, Mullen M, Neighbor WE, Cheadle AD: A multifaceted intervention in support of diabetes treatment guidelines: a cont trial. Diabetes Res Clin Pract 2002, 58(1):27-36.

63. King $A B$, Wolfe GS: Evaluation of a diabetes specialist-guided primary care diabetes treatment program. J Am Acad Nurse Pract 2009, 21(1):24-30.

64. Patric K, Stickles JD, Turpin RS, Simmons JB, Jackson J, Bridges E, Shah M: Diabetes disease management in medicaid managed care: A program evaluation. Dis Manag 2006, 9(3):144-156.

65. Pollard C, Bailey KA, Petitte T, Baus A, Swim M, Hendryx M: Electronic patient registries improve diabetes care and clinical outcomes in rural community health centers. J Rural Heal 2009, 25(1):77-84.

66. Schmittdiel JA, Uratsu CS, Fireman BH, Selby JV: The effectiveness of diabetes care management in managed care. Am J Manag Care 2009, 15(5):295-301.

\section{Pre-publication history}

The pre-publication history for this paper can be accessed here: http://www.biomedcentral.com/1472-6963/12/72/prepub

doi:10.1186/1472-6963-12-72

Cite this article as: Egginton et al: Care management for Type 2

diabetes in the United States: a systematic review and meta-analysis. BMC Health Services Research 2012 12:72.

\section{Submit your next manuscript to BioMed Central and take full advantage of:}

- Convenient online submission

- Thorough peer review

- No space constraints or color figure charges

- Immediate publication on acceptance

- Inclusion in PubMed, CAS, Scopus and Google Scholar

- Research which is freely available for redistribution

Submit your manuscript at www.biomedcentral.com/submit
Ciomed Central 